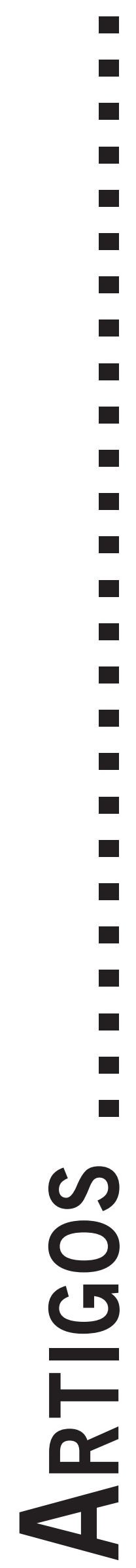




\title{
REVERSIBILIDADE ENTRE PERCEPÇÃO E EXPRESSÃO NA EXPERIÊNCIA CINEMATOGRÁFICA: A COMPLETAÇÃO GESTÁLTICA PARA CAMPO MULTIESTÁVEL
}

\author{
Reversibility Between Perception and Expression on Cinematograph Experience: \\ The Gestalt Completion to Multistable Field \\ Reversibilidad entre Percepción y Expresión en la Experiencia Cinematográfica: \\ la Compleción Gestalt para Campo Multi Estable
}

WiLLIAM B. GOMES

DANiEl RosemberG

Luciano da Silva Alencastro

Thiago Gomes de CAstro

\begin{abstract}
Resumo: A experiência cinematográfica é um campo multiestável que fornece tempo, sendo espaço uma ilusão perceptual. Assim, como se completa a Gestalt do espectador diante de um filme desprovido de diálogos conversacionais, mantendo-se apenas o diálogo tonal (uma provável estória) e expositivo (um provável contexto)? Vinte e seis estudantes de psicologia assistiram à exibição do curta-metragem "i”, do diretor e produtor gaúcho Paulo Zaracla (dois minutos de duração), e escreveram, em seguida, um relato livre sobre o filme. Os relatos obtidos foram considerados como expressão da mensagem do filme e analisados com base no critério triádico da fenomenologia semiótica (descrição, redução e interpretação). A descrição definiu as relações diacrônicas e as correlações sincrônicas dos relatos e entre relatos quanto à situabilidade, aos sentimentos, à resolução e à voz de enunciação. A redução especificou os gêneros literários escolhidos como contexto de expressão (conto, ensaio ou crônica). A interpretação suspendeu as sugestivas temáticas existenciais presentes para se concentrar nas relações psicofísicas e psicológicas na completação comunicativa da Gestalt, negociadas entre percepção e expressão. O uso de figuras ambíguas como demonstração de campo multiestável apenas exacerba a relação cotidiana entre modos processuais cognitivos na completação da Gestalt como demonstra a experiência cinematográfica.
\end{abstract}

Palavras-chave: Gestalt; Cinema; Fenomenologia; Semiótica; "i”.

Abstract: The cinematographic experience is a multistable field, which brings time, being space a perceptual illusion. How does the spectator complete a Gestalt of a film without conversational dialogue, but keeping the tonal (a probable story) and expositive (a probable context) dialogue? Twenty six undergrad students of psychology watched an exhibition of a short motion picture called "i", directed by Paulo Zaracla. They were asked to write a reaction report, following the presentation. The obtained reports were considered as an expression of the film's message and analyzed through out the triadic criteria of the semiotic phenomenology (description, reduction and interpretation). The description defined the diachronic relations and the synchronic correlations within and between reports as situation, feelings, resolution, and voice of enunciation. The reduction specified the reports as literary genres, chosen as context of expression (short prose, essay or chronicle). The interpretation suspended the reports' suggestive and existential thematic to concentrate in the psychophysical and psychological streams through out Gestalt formation, a negotiation between spectator's perception and expression. The use of ambiguous figure as a demonstration of a multistable field is a way to exacerbate the everyday relation between procedural cognitive modes of Gestalt formation as demonstrated by the cinematic experience.

Keywords: Gestalt; Cinema; Phenomenology; Semiotics; "i”.

Resumen: La experiencia cinematográfica es un campo multi estable que provee tiempo, siendo el espacio una ilusión perceptiva. ¿Cómo se completa la Gestalt del espectador delante de una película desprovista de diálogos de conversación, conservándose apenas el diálogo tonal (probable cuento) y expositivo (probable contexto)? Veintiséis estudiantes de psicología asistieron a la presentación de una película de corta duración llamada "i”, dirigida por Paulo Zaracla y enseguida escribieron un relato. Estos fueron considerados expresión del mensaje de la película y analizados por el criterio triádico de la fenomenología semiótica (descripción, reducción e interpretación). La descripción definió las relaciones diacrónicas y las correlaciones sincrónicas de los relatos y entre ellos en cuanto a la situación, los sentimientos, a la resolución y a la voz de enunciación. La reducción especificó los géneros literarios elegidos como contexto de expresión (cuento, ensayo o crónica). La interpretación suspendió las sugestivas temáticas existenciales presentes en los relatos para concentrarse en las relaciones psicofísicas y psicológicas en la complementación comunicativa de la Gestalt, negociadas entre percepción y expresión. El uso de figuras ambiguas como demostración de campo multi estable exacerba la relación cuotidiana entre modos procesales cognitivos en la complementación de la Gestalt como demuestra la experiencia cinematográfica.

Palabras-clave: Gestalt; Cinema; Fenomenología; Semiótica; “i”. 


\section{Introdução}

A percepção é a apreensão de sentido em um único lance na configuração momentânea da experiência. Neste único lance, se seleciona um número limitado de elementos que melhor atendam a informação sensorial na configuração de uma forma, esse sentido emergente e provisório. A expressão em imagens, palavras e gestos é a contrapartida dialógica na revisão continuada da informação perceptual que, por sua vez, atualiza o sentido na expressão e assim sucessivamente. Uma maneira atrativa e instigante para ilustração da reversão entre percepção e expressão na criação do sentido é a experiência de assistir a um filme. Essa experiência se torna ainda mais interessante quando se recorre a um filme sem diálogos, exacerbando a natureza multiestável do estímulo cinematográfico. O presente estudo investiga a reversão entre percepção e expressão na experiência de se assistir a um filme com instabilidade do campo perceptual pela intercalação e ambigüidade das imagens (montagem), exacerbadas pelo ritmo acelerado das ações em cena.

A idéia de campo multiestável vem do conhecido Cubo de Necker (Figura 1a), descoberto em 1832 por L. A. Necker (Einhäuser, Martin \& Köning, 2004), tornando-se posteriormente um dos princípios da psicologia Gestalt (Koffka, 1935). Por campo multiestável define-se um fenômeno visual ambíguo de interpretação reversível, de- pendendo do ponto no qual se fixa o olhar. Talvez a figura multiestável mais conhecida é a ilustração de Edgar Rubin (1886-1951) para o movimento entre as duas cores que levam a apreensão de conceitos como as faces ou o jarro (Figura 1b). Como amplamente conhecido, a dualidade conceitual ocorre pela reversão figura-fundo. No Cubo de Necker, a ambigüidade ocorre pela omissão do fundo, impedindo a delimitação do ângulo mais próximo. Outra figura muito conhecida é o triângulo impossível, na qual um objeto bidirecional remete ilusoriamente para uma projeção tridimensional (Figura 1c). Mesmo quando identificado como objeto impossível, a imagem permanece como tal. A configuração de um campo multiestável depara-se com um movimento de imagens que se resolve por completação ilusória, como ilustram as duas versões do triângulo de Kanizsa (Figuras 1d e 1e). No caso da Figura 1d, partes de um objeto estão camufladas por uma superfície subjacente com a mesma cor e luminosidade do entorno. A imagem é vista como se tivesse contorno. Na Figura 1e, a superfície de intercalação triangular aparece de forma idêntica, mesmo com a presença real dos contornos. Na imagem em movimento, como é o caso do cinema, a percepção se torna mais complexa ainda pelos efeitos do agrupamento gestáltico de sincronia e ligação (Palmer, 1999), proporcionados pelos recursos de montagem, posicionamento e efeito da câmera, e a movimentação da estória.

Figura 1. Campos multiestáveis

a)

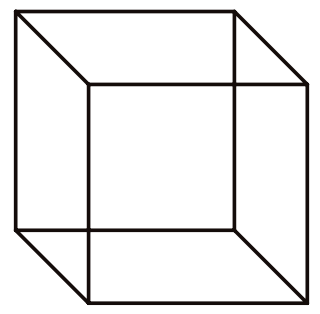

Ambiguidade perceptual: percepção multiestável - cubo de Neker (Fischler \& Firschein, 1987).

d)
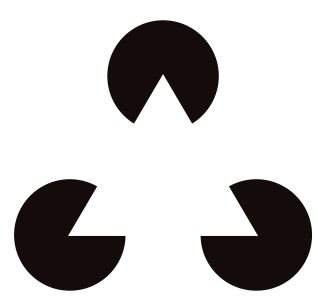

b)

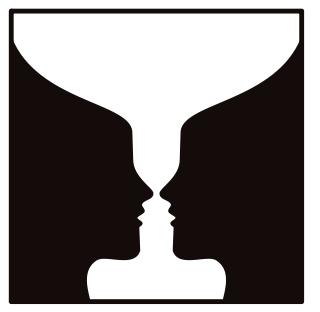

Ilustração de Rubin para o movimento entre figura e fundo.

e)

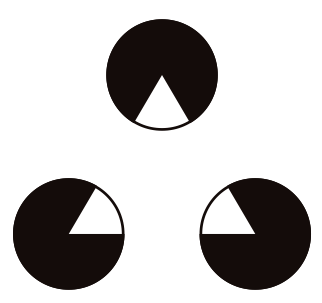

Triângulo de Kanizsa - Singh (2004) c)

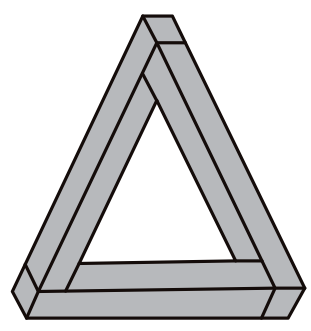

Triângulo impossível - (Fischler \& Firschein, 1987). 
As figuras ambíguas vêm sendo estudadas por psicofísicos (Fishler \& Firschein, 1987), oftalmologistas (Hol, Koene \& van Ee, 2003) e neurocientistas (Einhäuser, Martin \& König, 2004) como ilusões visuais. Ainda há, na literatura, uma enorme disputa para a explicação do fenômeno da reversão da percepção visual (Leopold \& Logothetis, 1999). A explicação mais aceita é que a reversão ocorre por meio de conectividade antagonista no sistema visual. Leopold e Logothetis (1999) argumentaram que a alternância perceptual espontânea deve-se a respostas ativas provenientes de áreas cerebrais que integram informação sensória e não-sensória para coordenar a diversidade de comportamentos. Trata-se de iniciativa espontânea, voluntária e influenciada pela experiência subjetiva como atenção e humor. O processo de alternância é sensível à prática e comprometido no caso de lesões em áreas corticais não visuais. Caracteriza-se por uma dinâmica temporal semelhante àquelas de comportamentos iniciados espontaneamente. De acordo com os autores, estudos com imagens funcionais mostraram que quando a visão se torna instável ativam-se áreas cerebrais associadas a uma variedade de atividades cognitivas. Deste modo, a reorganização da atividade do córtex visual decorrente de reversões perceptuais é uma iniciativa de centros cerebrais superiores. Ocorre uma intervenção no processo sensório para o planejamento da ação motora, com conseqüências imediatas na organização perceptual, principalmente no que se refere à atenção seletiva.

A Gestalt da mensagem de um filme é sempre uma experiência multiestável, pois o filme apenas fornece o tempo, sendo o espaço uma decorrência perceptual ilusória (Lanigan, 1972). A perda da dimensão espacial durante a projeção de imagens produz oclusões e ilusões, propiciando grande variação nas formações gestálticas entre espectadores (Stingh, 2004). Na verdade, a Gestalt é uma organização espontânea que supera a distinção entre passividade e atividade, e entre subjetividade e objetividade (MerleauPonty, 1945/1996). Ela traz um dinamismo próprio que, ao se especificar, determina os próprios limites. A experiência cinematográfica oferece uma oportunidade única de fusão na qual o espectador está e não está na história, podendo falar de dentro e de fora do filme (Sobchack, 1992). Ao apresentar-se a experiência cinematográfica, o espectador atende a uma Gestalt na qual a história dele e a história do filme se encontram para um entrelaçamento cúmplice ou para um distanciamento crítico. De qualquer modo, o filme certamente desencadeará um processo reflexivo no qual o espectador se tornará o centro, podendo estar simultaneamente dentro e fora do filme.

O cinema se estrutura em três tipos de diálogos (Lanigan, 1972): o diálogo expositivo, que aponta para as circunstâncias que compõem a cena; o diálogo tonal, que estabelece o padrão narrativo dos protagonistas; e o diálogo dramático, que estrutura a relação conversacional entre os vários protagonistas. Cada tipo de diálogo implica em um modo de interferência na completação da Gestalt. A ênfase no diálogo expositivo pode duplicar a natureza multivariada do campo experiencial; a ênfase no diálogo tonal pode esvaziar a cena e esmaecer o sentido fílmico; a ênfase na dramaticidade, a mais presente nos filmes, pode perder a sincronia com os demais diálogos e comprometer a mensagem. Os três tipos de diálogos podem enriquecer, empobrecer, ou mesmo negar a articulação entre percepção e expressão na experiência gestáltica do espectador.

O presente estudo trata da experiência gestáltica do espectador diante de um filme desprovido de diálogos conversacionais, mantendo-se apenas o diálogo tonal e expositivo. Ao omitir o diálogo conversacional, oferecemse apenas imagens e sons. Neste vazio, transfere-se o diálogo conversacional ao espectador que com um relato livre deverá dar palavras ao filme. $\mathrm{O}$ objetivo da pesquisa foi o levantamento da mensagem do filme, enquanto uma Gestalt configurada em estratos, onde os elementos do filme e da imaginação do espectador se completariam. A expectativa de pesquisa era de que a carga emocional do filme mobilizasse a atenção, levando a reflexão sobre a vida, o outro e a si mesmo. Obviamente, esperava-se que os relatos trouxessem mensagens variadas, recorrendo ou ultrapassando os elementos do filme, como ocorre na decodificação de mensagens na vida cotidiana. No entanto, a idéia era alcançar esses resultados com um filme de curta metragem, com superposição de montagens, câmera ágil e muita ação.

\section{Método}

O filme exibido na pesquisa foi o curta-metragem "i”, do diretor e produtor gaúcho Paulo Zaracla (2006), rodado em Porto Alegre, com duração de dois minutos. Por conseguinte, a história se passa em um cenário urbano e explora a estética da velocidade, da paranóia e do imaginário. O filme se caracterizava como um campo multiestável pela intermitência entre seus elementos estáveis e instáveis na completação gestáltica. A sinopse, na compreensão dialogada entre os pesquisadores após assistir ao filme inúmeras vezes, é a seguinte:

A história inicia com um rapaz pagando sua corrida a um taxista. As portas traseiras do carro se abrem e surgem em cena dois homens supostamente idênticos. A seguir, dá-se uma rápida e violenta perseguição pelas ruas de Porto Alegre, onde perseguidor e perseguido freqüentemente se confundem. O frenesi continua até que um dos protagonistas sobe correndo as escadas de um prédio abandonado. Quando no topo do prédio, olha para baixo e visualiza seu símile caminhando pela rua, bem abaixo do ponto em que ele se localiza. Após um breve instante adquirindo fôlego, o protagonista se atira do alto terraço do edifício na direção de seu oponente. $\mathrm{O}$ salto é certeiro. O homem, que após a queda parece tornar-se novamente um só, levanta, olha ligeiramente para os lados, e segue em meio aos transeuntes caminhando por uma rua de Porto Alegre (Figura 2 traz algumas fotos do filme.) 
Figura 2. Cenas do curta-metragem “i” (Zaracla, 2006).
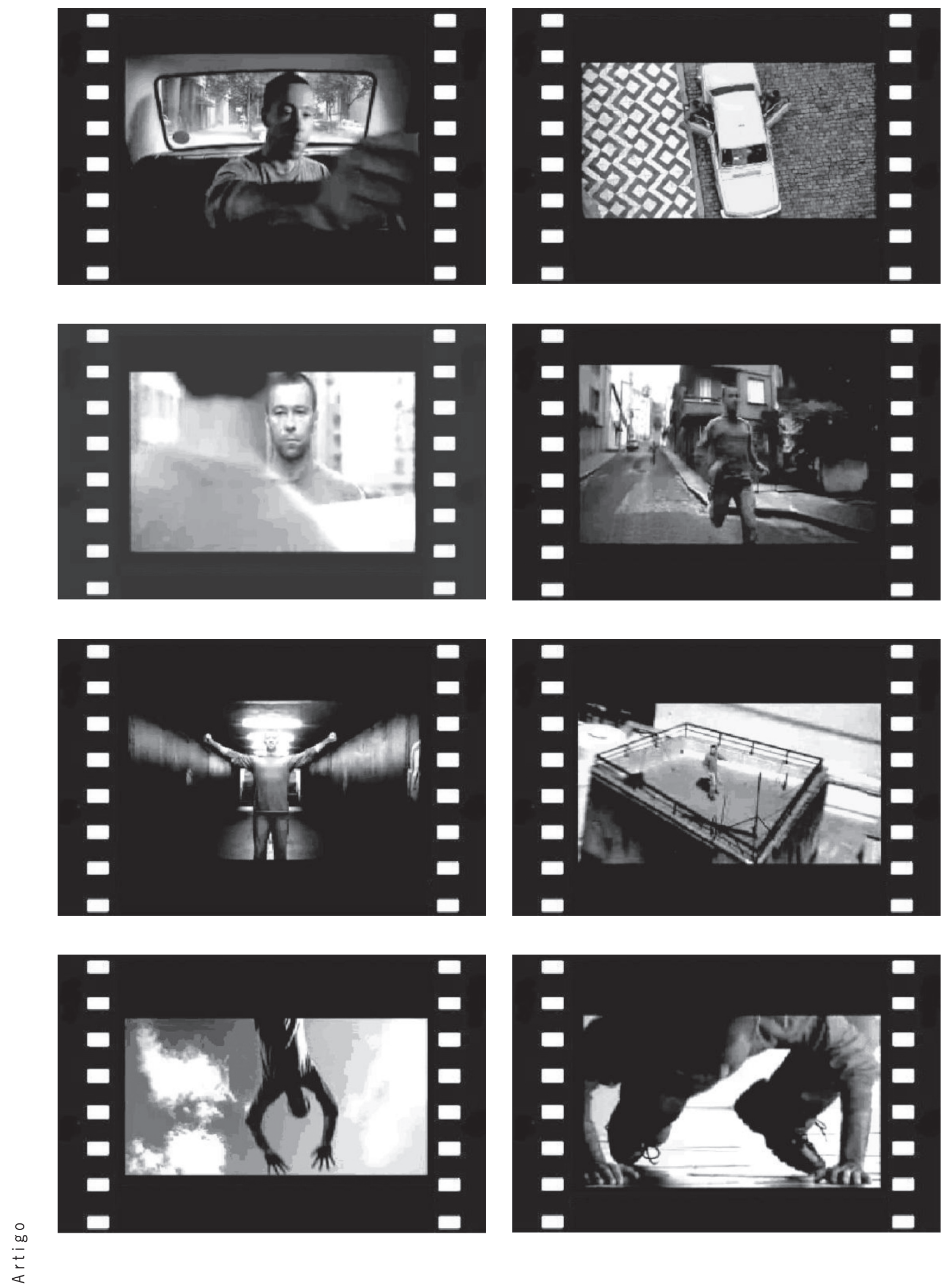
Assim, tem-se a ambigüidade entre homens, que parecem dois, mas podem ser um. Eles se separam e se juntam em cenas que se repetem ao longo do curta-metragem, sugerindo situações de pertencimento e ligação. De resto, a movimentação sugere perseguição, conflito, dúvida e reconciliação mágica.

Assistiram à exibição do filme, 26 alunos do primeiro semestre da graduação do Instituto de Psicologia da Universidade Federal do Rio Grande do Sul, com idade variando entre 17 e 19 anos, sendo dois maiores que 20 anos. A exibição ocorreu em sala de aula, no horário da disciplina Psicologia e Filosofia, no segundo semestre de 2007, com a utilização de um projetor multimídia. Tratando-se de uma pesquisa empírica teórica, não foram levadas em consideração diferenças de sexo, idade, horário de exibição e disciplina que cedeu parte do tempo para a pesquisa. A audiência recebeu folhas pautadas em branco e canetas esferográficas, sendo convidados para escrever um relato livre sobre o filme. A instrução foi a seguinte: "Assista ao filme que será exibido com o máximo de atenção e após o término do curta-metragem relate livremente o que lhe vier à cabeça”. Não foi delimitado tempo para a realização da tarefa. À medida que os participantes finalizavam suas produções escritas, recolhia-se o material, colocando-as em um envelope lacrado. Foram atendidos os requisitos éticos de consentimento livre e esclarecido. O critério de análise foi a fenomenologia semiótica (Lanigan, 1988). Referências à literatura e às informações técnicas da análise serão apresentadas junto aos resultados, quando pertinentes.

\section{Resultados}

Como esperado, os relatos interpretaram a mensagem do filme livremente, recorrendo a paralelismo e a metáforas. O menor relato utilizou $40(\mathrm{R} 4)^{1}$ palavras e o maior de 320 (R18), sendo a média de 142,19 palavras. Dois relatos foram escritos em forma de poesia, um deles em língua inglesa. Como esperado, elementos presentes no filme foram percebidos e expressos em diferentes enfoques e dilemas, nem sempre próximos à sinopse do filme, como entendida pelos pesquisadores. Os elementos centrais da trama estabeleceram a relação semiótica com o espectador: os dois homens supostamente idênticos, a correria pelas ruas da cidade; a confusão entre perseguido e perseguidor; o subir apressado as escadas do prédio; o salto certeiro do topo do prédio para o símile lá embaixo quando os dois se tornavam um. A incorporação ou referência aos elementos centrais foi dispersa, aparecendo relatos voltados a um único elemento ou alheio aos motivos do enredo. De qualquer modo, o filme passou aos participantes uma mensagem de fuga, de perseguição, de isolamento, de duplicidade, de reconhecimento das várias partes de si mesmo e das

\footnotetext{
Os códigos referem-se a numeração dada aos participantes, como aparece na Tabela 1.
}

dificuldades no diálogo entre elas. Houve relatos que receberam títulos: "O eu e o balão de abelhas", "O encontro"; "Delira Samuel, delira”; ou "A corrida do caos". Desse modo, temos para análise o diálogo que se estabelece entre a percepção do filme e a expressão do texto, sendo a captação da mensagem a Gestalt radical.

O filme enquanto oferta perceptual é uma mediação semiótica, isto é, um sistema de significações (Lanigan, 1997; Martin, 2003). É uma linguagem, um sistema de códigos que leva uma mensagem alcançável por meio da decodificação: a interpretação. Em outras palavras, o filme é uma conjunção entre um sistema de códigos e um sistema de significação. No envio de uma mensagem, tem-se de um lado a semiótica como ciência objetiva dos códigos ou signos, e do outro, a fenomenologia como a ciência compreensiva do que está sendo dito e visto. A decodificação realiza-se na movimentação seletiva entre o fluxo diacrônico (a relação de continuidade entre as imagens) e as permutações entre as sincronias possíveis (a simultaneidade dos elementos das cenas), produzindo as variações interpretativas. Tal articulação permite que se considerem tanto os elementos objetivos dos signos (quantidades), quanto às aplicações subjetivas (qualidades). Por sua vez, o texto enquanto manifestação expressiva é também uma mensagem em sua completude, mas reduzida em escopo se comparada ao filme. O código é restrito à linguagem verbal escrita. Na sua composição básica e para efeitos de comparação, o texto pode ser diferenciado quanto à estrutura (o que é constante na manifestação), e à substância (o que é variável na manifestação).

Tendo enunciado que o filme está sendo tomado como percepção e o texto como expressão, podemos dar início à análise fenomenológica semiótica. Note-se, contudo, que para os pesquisadores o texto dos participantes funciona como percepção e o presente artigo como expressão oferecida à percepção dos presumíveis leitores. A análise fenomenológica seguirá os três passos usuais (Gomes, 1998): 1) descrição compreensiva dos relatos; 2) redução para o que é estável e para o que é instável no confronto entre o filme e o relato; e 3) interpretação da Gestalt frente ao filme como experiência multiestável. Na verdade, cada um desses passos inclui todos os três, pois a análise é sistemática e sistêmica, isto é, das partes para o todo e do todo para as partes.

\section{Descrição}

A análise descritiva concentrou-se na distinção entre as partes estruturais estáveis e as variações encontradas nos relatos. Reduziu-se a estrutura geral dos relatos a quatro partes interligadas em hierarquia e em função: 1) a situação indicada pelo participante de onde, quando e como ocorreu a história; 2) os sentimentos manifestos no relato; 3) a resolução do episódio; e 4) a voz de enunciador. A identificação e nomeação das partes não foram 
atribuídas por árbitros neutros, mas por negociação abdutiva e impregnada dos pesquisadores e autores da presente análise. Interpretou-se que as quatro partes seriam suficientes para indicar como ocorreu a decodificação da mensagem do filme. A descrição fenomenológica aparece em síntese na Tabela 1, com as funções semióticas indicadas na horizontal e na vertical: respectivamente, movimento sintagmático (a singularidade de um relato como diacronia), e movimento paradigmático (a pluralidade dos relatos como alternâncias sincrônicas).

Tabela 1. Descrição sintética relação estrutural entre espectador e filme.

\begin{tabular}{|c|c|c|c|c|}
\hline$P$ & $\begin{array}{c}\text { Gênero literário / } \\
\text { Situação }\end{array}$ & Sentimento & Resolução & Enunciador \\
\hline 1 & $\begin{array}{l}\text { Crônica } \\
\text { Durante a vida travamos- } \\
\text { perseguições e fugas de nós } \\
\text { mesmos }\end{array}$ & $\begin{array}{l}\text { Há um eu obscuro, ameaça- } \\
\text { dor que atrai, mas que pre- } \\
\text { ferimos desconhecer }\end{array}$ & $\begin{array}{l}\text { Descartar ilusões, buscar } \\
\text { o real ou tentar o obscuro, } \\
\text { mas comprometer nossa } \\
\text { existência. }\end{array}$ & $\begin{array}{l}1^{\text {a }} \text { Pessoa Plural - Aborda } \\
\text { os vários eus e os riscos do } \\
\text { conhecimento pleno de si }\end{array}$ \\
\hline 2 & $\begin{array}{l}\text { Ensaio } \\
\text { Ir para a rua: fuga }\end{array}$ & $\begin{array}{l}\text { Eu sou a rua, sou tantos que } \\
\text { não sou nenhum, } \\
\text { Sofrimento }\end{array}$ & $\begin{array}{l}\text { O sonho da rua acaba e tudo } \\
\text { volta ao normal }\end{array}$ & $\begin{array}{l}1^{\text {a }} \text { Pessoa Singular - Usa } \\
\text { elementos do filme e se } \\
\text { coloca nele }\end{array}$ \\
\hline 3 & \begin{tabular}{|l|} 
Conto \\
Wagner o premiado \\
Cria um personagem e con- \\
ta a história \\
\end{tabular} & & Wagner suicida-se & $\begin{array}{l}3^{\text {a }} \text { Pessoa - História parale- } \\
\text { la, em cima do elemento do } \\
\text { filme: jogou-se do prédio }\end{array}$ \\
\hline 4 & $\begin{array}{l}\text { Ensaio } \\
\text { Um filme com perseguição } \\
\text { de personagens }\end{array}$ & & $\begin{array}{l}\text { Joga-se do prédio, estatelan- } \\
\text { do-se no chão }\end{array}$ & $\begin{array}{l}3^{\text {a }} \text { Pessoa - Faz um paralelo } \\
\text { com o filme "Os infiltrados" }\end{array}$ \\
\hline 5 & $\begin{array}{l}\text { Ensaio } \\
\text { Vontade de isolamento } \\
\text { Fuga de nós mesmos. }\end{array}$ & $\begin{array}{l}\text { A insuportável visão do que } \\
\text { às vezes somos, como se } \\
\text { bastasse fugir para resolver }\end{array}$ & $\begin{array}{l}\text { Não há solução, talvez acei- } \\
\text { tar os vários que somos }\end{array}$ & $\begin{array}{l}1^{\text {a }} \text { Pessoa Plural - Destaca a } \\
\text { importância dos vários para } \\
\text { que possa ser um }\end{array}$ \\
\hline 6 & $\begin{array}{l}\text { Conto } \\
\text { Correr, fugir dos sentimen- } \\
\text { tos. }\end{array}$ & A paz além do alcance & $\begin{array}{l}\text { Infelicidade intensa, como } \\
\text { sempre foi e sempre será }\end{array}$ & $\begin{array}{l}3^{\text {a }} \text { Pessoa - Descreve uma } \\
\text { cena }\end{array}$ \\
\hline 7 & $\begin{array}{l}\text { Conto } \\
\text { Manhã de inverno: ela sen- } \\
\text { tada perto da janela, toman- } \\
\text { do café com pães de queijo, } \\
\end{array}$ & Esperando & $\begin{array}{l}\text { Olhando, refletindo [em } \\
\text { aberto] }\end{array}$ & $\begin{array}{l}3^{\text {a }} \text { Pessoa - Descreve uma } \\
\text { cena, vaga, parece não se } \\
\text { resolver }\end{array}$ \\
\hline 8 & $\begin{array}{l}\text { Ensaio } \\
\text { Um texto para escrever de- } \\
\text { pois de assistir ao filme "i" }\end{array}$ & $\begin{array}{l}\text { Preocupação em como es- } \\
\text { crever o texto }\end{array}$ & $\begin{array}{l}\text { Um dos textos mais deliran- } \\
\text { tes que já escreveu }\end{array}$ & $\begin{array}{l}1^{\text {a }} \text { Pessoa - Reflete sobre a } \\
\text { tarefa de escrever um texto }\end{array}$ \\
\hline 9 & $\begin{array}{l}\text { Ensaio } \\
\text { Há coisas em nós que doem, } \\
\text { que nos envergonham. }\end{array}$ & $\begin{array}{l}\text { Vida é desagradável se acei- } \\
\text { ta sem fuga, cheira mal. }\end{array}$ & $\begin{array}{l}\text { A corrida só acaba de duas } \\
\text { maneiras: morte ou vômito }\end{array}$ & $1^{\text {a }}$ Pessoa no plural \\
\hline 10 & $\begin{array}{l}\text { Ensaio } \\
\text { Alguém que foge do próprio } \\
\text { desejo ou do que esperam } \\
\text { dele } \\
\end{array}$ & $\begin{array}{l}\text { Volúvel: entre fazer o que } \\
\text { quer e o que os outros que- } \\
\text { rem }\end{array}$ & $\begin{array}{l}\text { De quantos prédios precisa- } \\
\text { mos saltar para encontrar o } \\
\text { equilíbrio? }\end{array}$ & $\begin{array}{l}3^{\text {a }} \text { Pessoa - Reflexivo, traba- } \\
\text { lha com elementos do filme }\end{array}$ \\
\hline 11 & $\begin{array}{l}\text { Conto } \\
\text { O mendigo era eu }\end{array}$ & $\begin{array}{l}\text { "Olhava para mim mesma”, } \\
\text { sensação de ser igual a } \\
\text { mendigo }\end{array}$ & $\begin{array}{l}\text { Uma pessoa querendo so- } \\
\text { breviver sem superioridade }\end{array}$ & $\begin{array}{l}1^{\text {a }} \text { Pessoa - Inclusão de per- } \\
\text { sonagem }\end{array}$ \\
\hline 12 & $\begin{array}{l}\text { Conto } \\
\text { Uma face, uma fuga. Um } \\
\text { picadeiro e o circo }\end{array}$ & $\begin{array}{l}\text { Sair do picadeiro, apreen- } \\
\text { são, nervosismo, inquieta- } \\
\text { ção, desfazer a máscara }\end{array}$ & $\begin{array}{l}\text { Decidiu-se. Pegou a maquia- } \\
\text { gem e começou a refazer o } \\
\text { rosto.. }\end{array}$ & $\begin{array}{l}3^{\text {a }} \text { Pessoa - Texto bem ar- } \\
\text { ticulado e metafórico. Um } \\
\text { conto. }\end{array}$ \\
\hline 13 & $\begin{array}{l}\text { Conto } \\
\text { Gêmeos brincando, diver- } \\
\text { tindo-se e competindo }\end{array}$ & Ganhar & $\begin{array}{l}\text { Encontro em família, onde } \\
\text { os gêmeos se encontram } \\
\text { com a avó, confraternização }\end{array}$ & $\begin{array}{l}3^{\text {a }} \text { Pessoa - Dá nome aos } \\
\text { dois personagens, na verda- } \\
\text { de irmãos gêmeos. }\end{array}$ \\
\hline
\end{tabular}




\begin{tabular}{|c|c|c|c|c|}
\hline 14 & Conto & & & $\begin{array}{l}\text { Não fala sobre o filme. A } \\
\text { narrativa é sobre a tarde } \\
\text { daquela quarta-feira, antes } \\
\text { da aula }\end{array}$ \\
\hline 15 & $\begin{array}{l}\text { Conto } \\
\text { Tomada de decisão }\end{array}$ & Dilema: ir ou não ir. & Não vai, prefere ficar. & $\begin{array}{l}3^{\text {a }} \text { Pessoa - Baseia-se na } \\
\text { duplicação de personagem: } \\
\text { os dois Ricardos }\end{array}$ \\
\hline 16 & $\begin{array}{l}\text { Ensaio } \\
\text { Doença da pressa, corrida } \\
\text { do caos. }\end{array}$ & $\begin{array}{l}\text { Correr atrás de si mesmo, } \\
\text { buscando um novo olhar. }\end{array}$ & $\begin{array}{l}\text { Continuar combatendo } \\
\text { em busca de anseios de si } \\
\text { mesmo: ansiedade, medo, } \\
\text { solidão. }\end{array}$ & $\begin{array}{l}1^{\text {a }} \text { Pessoa - Coloca-se dentro } \\
\text { do filme "corro atrás de } \\
\text { mim mesmo." }\end{array}$ \\
\hline 17 & $\begin{array}{l}\text { Ensaio } \\
\text { Fuga da consciência: Estar } \\
\text { acompanhado, mesmo que } \\
\text { sozinho. }\end{array}$ & Sempre diante de decisões & $\begin{array}{l}\text { Decisão correta, mesmo } \\
\text { que pareça errada é sempre } \\
\text { melhor }\end{array}$ & $\begin{array}{l}3^{\mathrm{a}} \text { plural - Reflexão sobre } \\
\text { tomada de decisão }\end{array}$ \\
\hline 18 & $\begin{array}{l}\text { Conto } \\
\text { Pelas ruas de Porto Alegre } \\
\text { um homem foge de si mes- } \\
\text { mo, perseguido pelo próprio } \\
\text { medo }\end{array}$ & $\begin{array}{l}\text { A constituição do duplo. } \\
\text { "Medo de ser, de não ser". } \\
\text { Avança contra si, com } \\
\text { ódio... }\end{array}$ & $\begin{array}{l}\text { Encontro com o inverso } \\
\text { de si. }\end{array}$ & $\begin{array}{l}3^{\text {a }} \text { Pessoa - Toma o mal-estar } \\
\text { da corrida do personagem } \\
\text { do filme, como o mal-estar } \\
\text { dos tempos atuais. }\end{array}$ \\
\hline 19 & $\begin{array}{l}\text { Crônica } \\
\text { Idéia do processo da forma- } \\
\text { ção de identidade. }\end{array}$ & $\begin{array}{l}\text { Fuga de nós mesmos, das } \\
\text { dúvidas, das incertezas. }\end{array}$ & $\begin{array}{l}\text { Quando se vai contra o que } \\
\text { é, acaba se descobrindo. }\end{array}$ & $\begin{array}{l}1^{\text {a }} \text { Pessoa - Reflexão sobre } \\
\text { a vida. }\end{array}$ \\
\hline 20 & $\begin{array}{l}\text { Crônica } \\
\text { "Um cara pode perseguir } \\
\text { ele mesmo." }\end{array}$ & $\begin{array}{l}\text { Não sou bobo. Estarão ten- } \\
\text { tando me enganar? Tenho } \\
\text { que contar uma história? }\end{array}$ & $\begin{array}{l}\text { Experiência de impessoa- } \\
\text { lidade. }\end{array}$ & $\begin{array}{l}1^{\text {a }} \text { Pessoa - Desconfiança em } \\
\text { relação ao pedido de escre- } \\
\text { ver sobre o filme. O que vão } \\
\text { pensar de mim? }\end{array}$ \\
\hline 21 & $\begin{array}{l}\text { Crônica } \\
\text { O próprio filme. }\end{array}$ & $\begin{array}{l}\text { Os múltiplos eus, papeis } \\
\text { que assumimos na socieda- } \\
\text { de e seus conflitos. }\end{array}$ & $\begin{array}{l}\text { Se o homem se encontrasse, } \\
\text { aí sim, poderia agir sobre } \\
\text { o mundo e não o mundo } \\
\text { sobre ele. }\end{array}$ & $\begin{array}{l}3^{\text {a }} \text { Pessoa - Atém-se ao enre- } \\
\text { do do filme. }\end{array}$ \\
\hline 22 & $\begin{array}{l}\text { Crônica } \\
\text { Confronto entre os eus, } \\
\text { partes em conflito. }\end{array}$ & Perseguição, morte. & $\begin{array}{l}\text { Ambivalente: uma das par- } \\
\text { tes parece ter deixado de } \\
\text { existir ou o sujeito sempre } \\
\text { foi único. }\end{array}$ & $3^{\text {a }}$ Pessoa - Expectador \\
\hline 23 & $\begin{array}{l}\text { Ensaio } \\
\text { "O poder de escolha" }\end{array}$ & $\begin{array}{l}\text { "O drama das escolhas" } \\
\text { Sofrer com decidir é melhor }\end{array}$ & "Como é bom escolher" & $\begin{array}{l}3^{\text {a }} \text { Pessoa - Reflexão sobre o } \\
\text { paradoxo da escolha }\end{array}$ \\
\hline 24 & $\begin{array}{l}\text { Conto } \\
\text { Um homem indeciso. }\end{array}$ & $\begin{array}{l}\text { Perseguição, fuga de si, can- } \\
\text { saço de duvidas sobe si. }\end{array}$ & $\begin{array}{l}\text { Comete suicídio, jogando-se } \\
\text { do prédio. }\end{array}$ & $\begin{array}{l}3^{\text {a }} \text { Pessoa - "Tudo não pas- } \\
\text { sou de um sonho." }\end{array}$ \\
\hline 25 & $\begin{array}{l}\text { "Outra" (Em inglês) } \\
\text { Aprendendo a andar em } \\
\text { uma bicicleta que terá asas }\end{array}$ & Alcançar o intangível. & $\begin{array}{l}\text { Paz de espírito é o caminho } \\
\text { da liberdade. }\end{array}$ & $\begin{array}{l}3^{\text {a }} \text { Pessoa - Escreve uma } \\
\text { fábula em inglês }\end{array}$ \\
\hline 26 & $\begin{array}{l}\text { "Outra" (Poesia) } \\
\text { Unindo as partes de si }\end{array}$ & $\begin{array}{l}\text { Dúvidas, questionamentos, } \\
\text { insistência }\end{array}$ & $\begin{array}{l}\text { As corridas da vida levam } \\
\text { ao encontro de si de onde } \\
\text { não se pode fugir }\end{array}$ & $\begin{array}{l}1^{\text {a }} \text { Pessoa - Escreve em } \\
\text { versos, como se fosse um } \\
\text { soneto }\end{array}$ \\
\hline
\end{tabular}

A coluna 2 da Tabela 1 traz a situação referida pelo contexto de escolha no qual ocorreu o episódio. Nos relatos, o contexto escolhido assumiu um tom grave (fuga, troca de identidades, múltiplos eus, drama das escolhas, caminho da liberdade, dilema), ou um tom ameno (brincadeira de gêmeos, manhã de inverno, ou Wagner o premiado). Indicou, também, o relacionamento do participante com o filme: manter distância; preferir lidar com os 
momentos que antecederam ao início da exibição e não propriamente com o filme; entender a tarefa como uma brincadeira; envolver-se efetivamente com o filme.

Em continuidade, a coluna 3 descreve os sentimentos que perpassavam os relatos. Foram sentimentos de ameaça, de despersonalização, de algo insuportável, de infelicidade intensa, de ansiedade, de dúvidas, de algo inatingível, de paz além do alcance; de olhar para o tempo. Note-se o paralelismo entre os sentimentos dos diferentes relatos, o que caracteriza a pluralidade dos relatos como alternâncias sincrônicas.

A coluna 4 focalizou a resolução, o desfecho do episódio oferecido pelos relatos. A resolução acentuou o mistério entre os personagens (era um ou eram dois?); o tom trágico (as referências ao suicídio, à falta de solução, à morte ou vômito, ou à infelicidade); o sonho que acabava; o combate que não terminava; o encontro de si, a paz de espírito. A resolução apresentou-se, ainda, como convite para refletir, refazer o rosto, levar adiante novas escolhas, ou para perguntar "de quantos prédios precisamos saltar para encontrar o equilíbrio" (R10). Novamente, a sincronia semiótica entre as resoluções é clara.

A coluna 5 concentrou-se no levantamento da voz do enunciador para estimar a medida qualitativa de imersão na narrativa, isto é: 1) falar de dentro, na primeira pessoa do singular, expondo-se ou envolvendo-se com a história, 2) falar de dentro, na primeira pessoa do plural, apontando para um envolvimento que parece de muitos; 3) ou falar de fora para manter a distância fria ou emocionada daquele que observa (terceira pessoa).

\section{Elementos Especificadores ou Redução Fenomenológica}

Para definir os elementos especificadores, os relatos foram reduzidos a gêneros literários, como definidos por qualquer gramática básica da língua portuguesa (por exemplo, Cegalla, 1987): conto, ensaio e crônica. O conto foi definido como forma narrativa em prosa, de menor extensão, que contenha os mesmos componentes de um romance (aventura, suspense, amor, ódio, etc). O ensaio foi definido como considerações críticas, com reflexões morais e filosóficas sobre o episódio. A crônica foi especificada como a visão pessoal do narrador, em estilo jornalístico, denotando diálogo direto com o leitor. Tecnicamente, tem-se aqui uma nova descrição, uma outra maneira de apreciar a estrutura em seu conjunto.

A análise dos elementos especificadores concentrouse nas funções semióticas do contexto literário escolhido pelo participante para decodificar a mensagem do filme. Hjelmslev (1961) definiu a função semiótica como uma dependência que atende as condições necessárias à realização de uma análise, sendo a análise uma descrição de um objeto pela dependência uniforme de outros objetos e entre eles. A função de um objeto para outro pode ser de hierarquia relacional ou correlacional. A hierarquia relacional é sintagmática, diacrônica e constitui um processo semiótico. A hierarquia correlacional é paradigmática, sincrônica e constitui um sistema semiótico. Em outras palavras, há relações entre os objetos (diacronia, seqüência) e entre as relações (sincronia, paralelismo). Neste estudo, os termos relação e correlação estão sendo utilizados para indicar a dependência ou não de elementos (objetos) do campo multiestável no relato. A dependência foi qualificada como explícita (predominantemente diacrônica), implícita (predominantemente sincrônica) ou não permanência (uma sincronia distanciada ou uma outra diacronia). Considerou-se dependência explícita quando a descrição da mensagem correspondeu diretamente aos trechos ou a totalidade do filme ('e' no filme/ 'e' no texto). Considerou-se dependência implícita quando a descrição da mensagem correspondeu indiretamente aos elementos do filme ('e/ou' no filme // 'e/ou' no texto). Considerou-se não dependência quando o relato distanciou-se demasiadamente dos elementos diretos (relação) ou indiretos (correlação) do filme.

A análise fenomenológico-semiótica leva obrigatoriamente ao confronto entre intensão ${ }^{2}$ (modo de percepção) e extensão (modo de expressão). A relação entre perceber (compreender) e expressar (manifestar) constitui a reversão comunicativa, na qual se produzem sentidos e se interpretam ou reinterpretam signos (Gomes, 1998). Essa relação passa pela objetividade da mediação semiótica, sendo possível apontar factualmente as relações entre os textos e os gêneros literários.

O número de produções textuais classificadas como contos foi similar à quantidade de permanência do estímulo caracterizada como implícita nos relatos (10 contos para 11 permanências implícitas). Pode-se inferir que pelo conto ser qualificado como narrativa - tendo como recurso de prosódia a formação de um enredo com início, meio e fim - os participantes tenham desenvolvido estórias ficcionais estimuladas pela interação entre a apresentação do curta-metragem e fatores inerentes ao padrão criativo e existencial deles. Ou seja, seguiram o estímulo eliciado pelo filme (e...e), mas com variações pontuais (ou...ou) no momento em que optaram por escrever seus relatos através do enredo de um conto.

A mesma lógica se deu através da comparação da produção de ensaios com a permanência explícita do estímulo. Sabe-se que o ensaio, como construção literária, tem como característica a introdução de novos elementos na busca de soluções exemplares para a problemática apresentada pelo autor, daí a pontuação do explícito para elucidar a aplicação imaginada. Tem-se então a acentuação das relações para justificar as correlações. O número de ensaios produzidos foi diretamente proporcional à permanência explícita do estímulo nas produções textuais (9 ensaios para 9 permanências explícitas).

\footnotetext{
Não confundir com intenção, termo usado em fenomenologia para indicar a direção da consciência ao objeto.
} 
A crônica caracteriza-se pelos posicionamentos assumidos pelo autor, mantendo autonomia e menor dependência aos elementos do filme. O que parece ter ocorrido nesses casos é que o campo multiestável providenciou ferramentas para a abertura de discussões mais amplas do que simples contextualizações do filme. Sendo assim, supõe-se que o curta-metragem foi desencadeador (e...e) de diferentes mensagens (ou...ou), as quais foram adaptadas a uma rede complexa de estilos cognitivos de cada participante. Este gênero literário confirmou o estabelecimento de um sistema semiótico incluindo o filme, os pesquisadores e os participantes. Das cinco crônicas apresentadas, quatro delas mantiveram uma relação de não dependência ou de menor dependência aos elementos do filme.

A seguir, ilustra-se a análise com exemplares de relatos classificados como conto, ensaio e crônica. Primeiro o conto.

Título: "Uma face e uma fuga"

"Saiu apreensivo e nervoso do centro do picadeiro. Caminhou pelo corredor com receio de que ele pulasse de trás da lona. Alguns passos rápidos sob a noite e estava no vagão que fazia as vezes de camarim.

Sentou-se à frente do espelho, molhou um lenço e começou a desfazer a máscara de maquiagem. Ao retirar a tira que recobria um olho, teve um relance do outro. Desfez um pouco mais da mascara, e confirmou suas suspeitas.

Um instante de inquietação, o coração trotando no peito. $O$ olho no espelho perscrutando-o, interrogando-o. Decidiu-se. Pegou a maquiagem e começou a refazer o rosto. O outro se escondeu sob uma espessa camada de pó-de-arroz.” (R12)

O relato foi classificado como conto, com enunciador na terceira pessoa e permanência implícita do campo multiestável, em razão da temática do texto não abordar diretamente o enredo do filme. A história foi situada em um circo, tratando da multiplicidade do self ("Teve um relance do outro, O outro se escondeu...”); do movimento sentido ("Caminhou pelo corredor com receio..., alguns passos rápidos...”) e conflituado (“Um instante de inquietação, o coração trotando no peito.”). A resolução foi positiva: "Decidiu-se. Pegou a maquiagem e começou a refazer o rosto.” A seguir o ensaio.

"Muitas vezes durante a vida temos vontade de isolamento ou de fugir de nós mesmos. Fuga desenfreada. Nossa própria visão, a visão de quem somos e como somos às vezes é insuportável. Como se bastasse correr muito. Correr no ritmo mais veloz possível, mais veloz que nosso eu, como que para deixá-lo para trás. Só que sem sucesso. Como mágica, ilusão, nos deparamos de novo com nossa imagem. Não há esconderijo suficientemente seguro, lugar suficientemente distante de nós mesmos. A sombra de nosso duplo nos ameaça e nos vai ameaçar sempre que tentarmos enganá-lo. Solução não sei se existe, mas incorporar nosso duplo ao invés de negálo, pode ser a forma mais leve, porém não a mais fácil, de viver com ele. Todos temos vários dentro de nós. E cada um desses vários é vital para podermos ser um. Aceitar os vários é o caminho para se chegar ao pleno". (R5)
Esse relato foi considerado como ensaio, com permanência explícita do campo multiestável e enunciador na primeira pessoa do plural. O estímulo deu vazão a divagações existenciais, tendo a fuga como situação, culminando com uma resolução dogmática. Dentre as variações temáticas destacam-se: multiplicidade do self ("A sombra de nosso duplo...; Todos temos vários dentro de nós.”), movimento ("Correr no ritmo mais veloz possível...;...para deixá-lo para trás”), conflito (“...como somos às vezes é insuportável.;...nos vai ameaçar sempre que tentarmos enganá-lo.”) e resolução (“Aceitar os vários é o caminho para se chegar ao pleno”). Por fim, a crônica.

Não consegui compreender com clareza o enredo da história; até porque- quem sabe, para esse curta - existam tantas interpretações quantas forem o número de espectadores. Me parece que, quando o personagem sai do táxi, e - olhando para o mundo (a cidade barulhenta, carros, pessoas) - "vem fora" um outro eu dele, um outro ele que o persegue e que ele não quer viver. Muitas vezes dentro de nós existem esses múltiplos "eus", esses papéis que no mundo assumimos. A sociedade capitalista, exige um homem ágil, eficiente, criativo, etc, etc, etc. Muitas vezes, exige-se o que o homem não é então esse entra em conflito, em uma fuga de si mesmo, pois não se reconhece e é movido por uma exigência que vem "de fora" e não por uma força interior. Quem sabe se o homem se encontrasse primeiro (encontrasse um "motor", uma motivação interna, um algo por o que viver) todas as suas ações - por mais variadas que fossem - teriam uma única intenção e, ao invés de ser comandado pelo mundo esses homens agiriam sobre ele (o mundo).

O relato foi classificado como crônica com uma relação de não dependência ao campo multiestável e com enunciador na terceira pessoa. O texto produzido parece ter sido embasado na ambigüidade suscitada pelo estímulo, embora seja eminentemente de caráter descritivo com impressões pontuais manifestas. O resultado é uma resolução dúbia, que isenta o autor de responsabilidade interpretativa. Dentre as variações temáticas identificadas, salienta-se: multiplicidade de self ("esses papéis que no mundo assumimos"), movimento ("vem de fora um outro eu dele"), conflito ("um outro eu que o persegue"), e resolução (o encontro de si mesmo).

\section{Interpretação fenomenológica}

A interpretação aponta imediatamente para o clamor temático que salta de relatos escritos por jovens que hoje atravessam uma longa adolescência até ingressar na vida adulta (Steinberg, 2005). Como se sabe, os conflitos inerentes a esse período do desenvolvimento são caracterizados por questões de identidade, de dificuldades de alocação no mundo, e de imposições para a integração produtiva e realizadora, tanto do mundo para o jovem quanto do jovem para o mundo. Não é espantoso que os textos se associem tão claramente ao presumível enredo do filme. 
Contudo, a interpretação deve ir além e esclarecer os modos cognitivos da apreensão do fenômeno multiestável e da força que aciona a reflexão, o poder semiótico (Wiley, 1994). A reunião de opostos no esboço estrutural oferecido pela descrição (situação, sentimentos, resolução, e voz de enunciação) e a redução dos relatos a modalidades descritivas (conto, ensaio e crônica) trouxeram subsídios importantes para a compreensão da decodificação da mensagem.

Estudos recentes em agrupamento gestáltico (Palmer, 1999) destacaram três processamentos específicos na completação da forma: 1) processamento de baixo para cima (bottom up processing); 2) processamento de cima para baixo (top down processing); e 3) concepções prévias. A percepção visual de estímulos complexos é o resultado de uma série de processamentos que transforma imagens captadas inicialmente em duas dimensões para imagens de três dimensões. A retina detecta elementos isolados que se apresentam ambíguos quando não associados a atributos como sombras, contornos e cores. A forma se completa com a integração das informações dos receptores da retina ao conhecimento prévio sobre o ambiente e junto a uma variedade de efeitos decorrentes do modo como os elementos são agrupados.

O processamento de baixo para cima é psicofísico, resultado da atividade elétrica produzida pela imagem retinal como registrada pelos receptores corticais (Schultz, 2004). A informação fenomenal é pobre e em duas dimensões. Quando a atividade elétrica alcança níveis mais profundos no córtex visual, ela se encontra com a informação armazenada na memória. Neste ponto, inicia-se o processamento de cima para baixo (Palmer, 1999) que é psicológico e combina a informação psicofísica com o conhecimento prévio do mundo visual. É no movimento entre esses processamentos que a imagem alcança a tridimensionalidade.

A relação entre as duas modalidades de processamento é complicada, com o processamento de cima para baixo equivocando-se na decodificação do processamento de baixo para cima. Curiosamente, os equívocos ocorrem por estratégias cognitivas cuja função é refinar a decodificação, como a familiaridade contextual e os esquemas conceituais (Palmer, 1999).

As concepções prévias que interferem na decodificação decorrem: 1) de condições inatas, aquelas que atravessam tempos, regiões e culturas; 2) de princípios clássicos de agrupamento gestáltico (proximidade, similaridade, direção, disposição objetiva, destino comum, e pregnância - ver Wertheimer, $1923^{3}$ ), e 3) de novos princípios de agrupamento como o princípio de sincronia (Bregman, 1990) e de ligação (Palmer \& Rock, 1994).

A experiência cinematográfica constitui-se em um paradoxo em que os limites presentes para a completação da Gestalt transformam-se em abertura para uma imaginação aparentemente livre, mas atrelada às condições

\footnotetext{
3 Os termos em português são da tradução de Álvaro Cabral para Marx e Hillix (1973).
}

processuais e determinantes da percepção: o sistema semiótico. No entanto, tal paradoxo projeta a relação de uma consciência corporificada, historicamente situada, na iminência de um porvir: o processo fenomenológico. O filme enquanto tal é um sentido em si, encerrando-se em si mesmo. A Gestalt que ele nos oferece é parcial, pois só inclui tempo, cabendo ao espectador intuir o espaço. Deste modo, a decodificação do filme é uma experiência pré-objetiva, tendo o próprio espectador como centro. $\mathrm{O}$ espectador apreende o tempo pelo presente que ele vive, percebe os outros através de si mesmo, vivendo uma emoção que transcende a ele mesmo. Entende-se, então, o interesse de psicólogos por figuras ambíguas na construção e utilização das técnicas projetivas, como um convite a expressão pré-objetiva do outro.

A ambigüidade da percepção da Gestalt temporal do filme sugeriu aos expectadores: 1) um tipo de relação (distância ou envolvimento), 2) um instante de instabilidade (perseguição, fuga, duplicidade, isolamento), e 3) um contexto (grave ou ameno). $\mathrm{O}$ filme foi a figura, e a experiência pré-objetiva de cada espectador o pano de fundo. Nos três pontos mencionados, tem-se a experiência objetiva na percepção da instabilidade, e a experiência subjetiva na escolha da relação e do contexto. A instabilidade foi dada ao espectador, mas foi ele que escolheu como se relacionar com ela e aonde deveria situá-la. Tem-se a fenomenologia do universal - a experiência objetiva (a instabilidade); e a fenomenologia do particular - a experiência pré-objetiva (como reagir a ela). A instabilidade trouxe a carga emocional que conferiu o poder semiótico para o envolvimento fenomenal com filme.

A expressão da Gestalt espacial apareceu nos relatos em forma de gêneros literários. Na realidade, o que se tem é a decodificação do tempo vivido de cada um, acrescido das condições de espaço para constituir uma Gestalt plena na relação com o outro, consigo e com o mundo.

\section{Epílogo}

O objetivo da pesquisa foi o levantamento da mensagem do filme para mostrar a dialogicidade entre seus elementos e a experiência do espectador. A novidade do estudo não está na proposição temática, mas na forma de análise. A análise mostrou que a completação da Gestalt visual se realiza por meio de processos cognitivos que integram a informação que chega até a retina para fundir-se, a seu modo, a conhecimentos anteriores. O refinamento crítico desta experiência decorre do círculo comunicativo na reversão entre percepção e expressão. Tal reversão se realiza na análise crítica de maior ou menor sofisticação e na decisão consciente ou não de reduzir a redundância e manter-se no estrito campo da mensagem; ou ainda analisar a mensagem e aplicá-la a si, ao outro, ou ao mundo. Na percepção das imagens cinematográficas a decodificação complica-se por aparecer destituída de espaço. 
É o conhecimento prévio que traz de volta o espaço. No entanto, como mostrou a literatura, as informações que chegam à retina são desconexas e só ganham sentido no encontro com o conhecimento prévio. Desse modo, as demonstrações de campo multiestável por meio de figuras (ver Figura 1) reproduzem e exacerbam a relação entre os processamentos de baixo para cima e de cima para baixo na completação da Gestalt. O novo enquanto tal é um desafio, é um esforço a ser continuamente perseguido. A exposição expressiva diante do ambíguo é pré-objetiva, colocando à descoberta as estratégias dialógicas vivenciais do enunciador. O eliciador emocional é a força que sustenta o interesse perceptivo e calibra o tom expressivo, na revelação ou no esconderijo de quem fala. Com efeito, o filme "i" é, como o próprio título sugere, um convite à reflexão de si, e é também recurso poderoso para o encontro dialógico em grupos vivenciais, sugerindo a reflexão dos nossos encontros e desencontros no grande campo multiestável em que vivemos.

\section{Referências Bibliográficas}

Bregman, A. S. (1990). Auditory Scene Analysis. Cambridge, MA: MIT Press.

Cegalla, D. P. (1987). Novíssima gramática da lingual portuguesa. São Paulo: Nacional.

Einhäuser, W., Martin, K. A. C., \& König, P. (2004). Are switches in perception of the Necker cube related to eye position? European Journal of Neuroscience, 20, 2811-2818.

Fishler, M. A., \& Firschein, O. (1987). Intelligence, The Eye, The Brain and The Computer. Boston: Addison-Wesley.

Gomes, W. B. (1998). Fenomenologia e pesquisa em psicologia. Porto Alegre: Editora da UFRGS.

Hjelmslev, L. (1961). Prolegomena to a theory of language. Madison: University of Wisconsin Press.

Hol, K., Koene, A., \& van Ee, R. (2003). Attention-biased multistable surface perception in three-dimensional structurefrom-motion. Journal of Vision 3, 486-498.

Koffka, K. (1935). Principles of Gestalt psychology. New York: Harcourt, Brace.

Lanigan, R. (1972). Speaking and semiology. Mouton: Paris

Lanigan, R. (1988). Phenomenology of communication. Pittsburgh, PA: Duquesne University Press.

Lanigan, R. (1997). Capta versus Data: Método e evidência em comunicologia (C. H. Kristensen, Trad.). Psicologia: Reflexão e Crítica, 10(1), 17-45.

Leopold, D. A. \& Logothetis, N. K. (1999). Multistable phenomena: Changing views in perception. Trends in Cognitive Sciences, 3(7), 254-264.

Martin, M. (2003). A linguagem cinematográfica. São Paulo: Brasiliense.
Marx M. H., \& Hillix, W. (1973). Teorias e sistemas em psicologia (A. Cabral, Trad.) São Paulo: Editora Cultrix. (Original publicado em inglês.)

Merleau-Ponty, M. (1996). Fenomenologia da percepção (C. Moura, Trad.). São Paulo: Martins Fontes. (Original publicado em francês, 1945).

Palmer, S. E. (1999). Vision Science: Photons to Phenomenology. Cambridge, MA: MIT Press.

Palmer, S. E. \& Rock, I. (1994). Rethinking perceptual organization: The role of uniform connectedness. Psychonomic Bulletin \& Review, 1, 29-55.

Schultz, M. F. (2004). Time course of perceptual grouping in user interface displays. Tese de doutorado não publicada, University of South Florida.

Stingh, M. (2004). Modal and amodal completion generate different shapes. Psychological Science, 15(7), 454-459.

Wertheimer, M. (1923). Laws of organization in perceptual forms. Em Christopher D. Greens (Org.). Classics in the history of psychology. Disponível em http://psy.ed.asu.edu/ classics-/ Wertheimer/Forms/forms.htm.

Wiley, N. (1994). The semiotic self. Chicago: The University of Chicago Press.

Steinberg, L. (2005). Adolescence. New York: McGraw-Hill Inc.

Sobchack, V. (1992). The Address of the eye: A Phenomenology of Film Experience. New Jersey: Princeton University Press.

Zaracla, P. (Diretor e Produtor). (2006). i. [Filme] Porto Alegre: Zeppelin Produções. Disponível em http://br.youtube.com-/ watch?v=4cUpUH8PYr0.

William Barbosa Gomes - Fundador e Coordenador do Laboratório de Fenomenologia Experimental e Cognição, Fundador e Professor do Programa de Pós-Graduação em Psicologia da Universidade Federal do Rio Grande do Sul.

Email: gomesw@ufrgs.br

Daniel Rosemberg - Psicólogo pela Universidade Luterana do Brasil (Canoas, 2005), Mestre em Psicologia pela Universidade Federal do Rio Grande do Sul (2008). Foi pesquisador no Laboratório de Fenomenologia Experimental e Cognição entre 2006 e 2008.

Email: danielrosemberg@yahoo.com

Luciano da Silva Alencastro - Psicólogo pela Universidade Federal do Rio Grande do Sul (2007), Pesquisador do Laboratório de Fenomenologia Experimental e Cognição e Mestrando em Psicologia na Universidade Federal do Rio Grande do Sul.

Email: lu.alen@yahoo.com.br

Thiago Gomes de Castro - Psicólogo pela Universidade Federal do Rio Grande do Sul (2005), Especialista em psicoterapia fenomenológicoexistencial pelo Centro de Psicoterapia Existencial (2006), Pesquisador do Laboratório de Fenomenologia Experimental e Cognição, e Mestrando em Psicologia na UFRGS.

Email: thiago.cast@gmail.com

Recebido em 14.09.08 Aprovado em 20.12.08 